\title{
Correction to: Towards pixel-to-pixel deep nucleus detection in microscopy images
}

Fuyong Xing ${ }^{1 *}$, Yuanpu Xie ${ }^{2}$, Xiaoshuang Shi ${ }^{2}$, Pingjun Chen ${ }^{2}$, Zizhao Zhang ${ }^{3}$ and Lin Yang ${ }^{2,3}$

\section{Correction to: BMC Bioinformatics (2019) 20:472 https://doi.org/10.1186/s12859-019-3037-5}

Following publication of the original article [1], we have been notified of a few errors in the html version:

- The captions for Fig. 1 and Fig. 2 have been switched

- The references to Fig. 1 and Fig. 2 have been switched within the main text

The pdf version of the article is correct. The original article has been corrected.

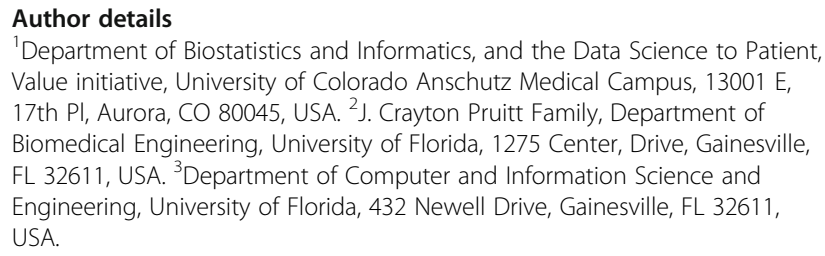

'Department of Biostatistics and Informatics, and the Data Science to Patient, Value initiative, University of Colorado Anschutz Medical Campus, $13001 \mathrm{E}$, 17th PI, Aurora, CO 80045, USA. ${ }^{2}$ J. Crayton Pruitt Family, Department of Biomedical Engineering, University of Florida, 1275 Center, Drive, Gainesville, FL 32611, USA. ${ }^{3}$ Department of Computer and Information Science and Engineering, University of Florida, 432 Newell Drive, Gainesville, FL 32611, USA.

Published online: 22 October 2019

\section{Reference}

1. Xing F, et al. Towards pixel-to-pixel deep nucleus detection in microscopy images. BMC Bioinformatics. 2019;20:472. https://doi.org/10.1186/s12859019-3037-5.

\footnotetext{
* Correspondence: fuyong.xing@ucdenver.edu

${ }^{1}$ Department of Biostatistics and Informatics, and the Data Science to Patient, Value initiative, University of Colorado Anschutz Medical Campus, $13001 \mathrm{E}$, 17th PI, Aurora, CO 80045, USA

Full list of author information is available at the end of the article
}

C The Author(s). 2019 Open Access This article is distributed under the terms of the Creative Commons Attribution 4.0 International License (http://creativecommons.org/licenses/by/4.0/), which permits unrestricted use, distribution, and reproduction in any medium, provided you give appropriate credit to the original author(s) and the source, provide a link to the Creative Commons license, and indicate if changes were made. The Creative Commons Public Domain Dedication waiver (http://creativecommons.org/publicdomain/zero/1.0/) applies to the data made available in this article, unless otherwise stated. 